\title{
Prognostic significance of claudin-1 and cyclin B1 protein expression in patients with hypopharyngeal squamous cell carcinoma
}

\author{
WUJIE LI ${ }^{1,2}$, QING DONG $^{3}$, LEI LI $^{4}$, ZHENLEI ZHANG $^{2}$, XIAOLAN CAI $^{1}$ and XINLIANG PAN ${ }^{1}$ \\ ${ }^{1}$ Department of Otolaryngology, Qilu Hospital of Shandong University, Jinan, Shandong 250012; \\ Departments of ${ }^{2}$ Otolaryngology, ${ }^{3}$ Pediatrics and ${ }^{4}$ Gastroenterology, \\ Tai'an City Central Hospital, Tai'an, Shandong 271000, P.R. China
}

Received January 23, 2015; Accepted February 19, 2016

DOI: $10.3892 / 01.2016 .4333$

\begin{abstract}
Claudin-1 and cyclin B1 are abnormally expressed in certain malignancies, but their expression in hypopharyngeal squamous cell carcinoma (HSCC) has not been reported thus far. Studying the expression levels of claudin-1 and cylin B1 in HSCC tissues and their association with clinical stage, pathological grade and prognosis in patients with HSCC may provide a theoretical basis and guide future research on HSCC targeted therapy. The protein expression levels of the above two biomarkers was immunohistochemically detected in 97 HSCC cases and 90 matched adjacent tissue samples. The correlation between the expression levels of claudin-1 and cylin B1 and the patients' clinical parameters was analyzed via Pearson's $\chi^{2}$ test, while survival analysis was performed using a log-rank test. The results of the current study revealed that claudin-1 and cyclin B1 were highly expressed in HSCC tissues, and the expression of claudin-1 was associated with tumor differentiation degree and lymph node metastasis, while cyclin B1 expression was associated with tumor differentiation degree. Furthermore, Kaplan-Meier analysis revealed that claudin-1 expression correlated with survival $(\mathrm{P}=0.003)$, and the expression levels of claudin-1 and cyclin B1 were observed to be positively correlated, in patients with HSCC. Cyclin B1 and claudin-1 exhibited an elevated expression in HSCC specimens, thus suggesting their use as tumor markers. Therefore, the joint detection of claudin-1 and cyclin B1 may aid to guide cancer therapy and to determine prognosis in HSCC. Furthermore, claudin-1 may be used as an HSCC-monitoring index, and may serve as a therapeutic target.
\end{abstract}

Correspondence to: Professor Xinliang Pan, Department of Otolaryngology, Qilu Hospital of Shandong University, 107 West Wenhua Road, Jinan, Shandong 250012, P.R. China

E-mail: panxinlent@126.com

Key words: hypopharyngeal squamous cell carcinoma, claudin-1, cyclin B1, immunohistochemical

\section{Introduction}

Head and neck squamous cell carcinoma is the sixth most common malignancy in the world (1), and accounts for 6-7\% of all malignant tumors (2). Hypopharyngeal squamous cell carcinoma (HSCC) accounts for $\sim 5 \%$ of all head and neck malignant tumors (3). Although the incidence of HSCC is low, the location of the primary tumor tends to be concealed, thus being difficult to locate accurately, which results in a late diagnosis for the majority of patients, once a tumor located near a neck lymph node has metastasized (4). At present, the majority of patients with HSCC are surgically treated with radiation therapy or a comprehensive chemical treatment method (5). However, these approaches result in a poor prognosis, and $\sim 1 / 2$ of patients experience a recurrence within 1 year $(3,6,7)$. Additionally, patient's word pronunciation, breathing and swallowing functions are severely affected or lost, thus seriously impacting their quality of life and long-term survival (8). Therefore, the identification of novel tumor markers may aid the earlier detection and improved treatment of this disease (9).

Tight junctions (TJs) exist between epithelial and endothelial cells, and function as a barrier to maintain a cellular steady-state and cell polarity (10). These junctions are mainly composed of three types of membrane proteins, including occludin, which is a member of the claudin family of proteins and junctional adhesion molecules (11). Claudin proteins are major barrier proteins (12) whose numbers and distribution directly affects the structure and function of TJs within the cell membrane (13). In various tumors, abnormal claudin expression alters TJ structure and function, causing a disruption in cell polarity and a decrease in cell adhesion, thus enhancing the invasive and metastatic potential of tumor cells (14). Among the claudin proteins, claudin-1 has been observed to be expressed at different levels in different tumors (15). It has been reported that claudin-1 is overexpressed and promotes tumor development in renal cell carcinoma (16), ovarian cancer (17), gastric adenocarcinoma (18) and colorectal cancer $(19,20)$. However, in breast cancer $(21,22)$ and lung adenocarcinoma (23), claudin-1 expression was previously reported to be significantly reduced. These differences in expression levels have been confirmed by 
other studies, and closely correlate with tumor occurrence and development $(24,25)$.

The cell cycle in normal cells is regulated by specific cyclins and cyclin-dependent kinases (CDKs), and exhibits an orderly start and end (26). By contrast, malignant cells are characterized by uncontrolled proliferation due to a loss of cell cycle regulation $(27,28)$. Cyclin B1 is a cell cycle protein involved in checkpoint control, promotion of the G2/M phase transition and acceleration of the cell cycle (29). Previous studies have demonstrated that cyclin B1 is overexpressed in numerous malignancies, including breast (30), gastric (31), early non-small cell lung (32), colorectal (33) and prostate cancer (34). Furthermore, uncontrolled cyclin B1 expression is closely associated with transformation and malignant proliferation of tumor cells $(35,36)$, and its overexpression is associated with poor prognosis in esophageal $(37,38)$, tongue and lung cancer (39). These findings suggest that cyclin B1 may be a useful tumor diagnostic marker.

However, the potential associations between the expression levels of claudin-1 and cylin B1 in HSCC and the clinical stage, pathological grade and prognosis of patients remain to be examined. Therefore, the present study examined the expression levels of cyclin B1 and claudin-1 in 97 HSCC tissue samples and 90 adjacent noncancerous tissue samples using immunohistochemistry (IHC), in order to determine the associations between the expression levels of these proteins and the patients' clinical stage, pathological features and prognosis. The present findings may aid the early diagnosis and prognosis of HSCC, and may guide future studies on targeted tumor therapy.

\section{Materials and methods}

Patients and sample collection. A total of 97 malignant tumors and 90 adjacent noncancerous tissue specimens (mucosae) from patients who had undergone surgical treatment for primary HSCC at Qilu Hospital of Shandong University (Jinan, China) were obtained from January 2008 to April 2010. All specimens were formalin-fixed (Hubei Xingfa Chemicals Group Co., Ltd., Hubei, China) and paraffin-embedded (Beijing Yanshan Yanya Chemical Sales Center, Beijing, China). The patients enrolled in the present study had not received neoadjuvant chemotherapy or radiation therapy prior to surgery. All individuals were treated by standard radical surgery with negative margins, and were administered 50-65 Gy radiotherapy post-operatively (KDS Medical Linear Accelerator; Siemens, Munich, Germany). The tumor-node-metastasis (TNM) classification of tumor samples was conducted in accordance with the guidelines published by the International Union Against Cancer in 2002 (40). Patients were followed-up for 3-5 years, and TNM staging was monitored during this period. The mean age of patients was 58 years, and the age range was 37-78 years. Patients' age, gender, pathological grade and clinical stage are presented in Tables I and II. Pathological grade was independently evaluated by two experienced pathologists (Department of Pathology, Tai'an City Central Hospital, Ti'an, China). The present study was approved by the Ethics Committee of Qilu Hospital of Shandong University (Jinan, China; approval no. 103-2008), and written informed consent was obtained from the patients' families.
IHC staining. Immunostaining was performed with rabbit anti-human polyclonal antibodies against claudin-1 (catalogno. ZA-0365; 1:100) and cyclin B1 (catalog no. ZA-0384; 1:100), which were purchased from Beijing Zhongshan Golden Bridge Biotechnology Co., Ltd. (Beijing, China), according to the manufacturer's protocol. Tissue sections were incubated at $62^{\circ} \mathrm{C}$ for $30 \mathrm{~min}$, deparaffinized in xylene (Beijing Zhongshan Golden Bridge Biotechnology Co., Ltd.) and rehydrated in graded alcohol prior to pretreatment with $3 \%$ hydrogen peroxide in phosphate-buffered saline (PBS) for $15 \mathrm{~min}$ to block endogenous peroxidase activity. Next, sections were washed 3 times in PBS, and heated in a microwave oven in the presence of $0.01 \mathrm{M}$ citric acid buffer $\mathrm{pH} 6.0$ (in the case of cyclin B1; Beijing Zhongshan Golden Bridge Biotechnology Co., Ltd.) or ethylenediaminetetraacetic acid buffer $\mathrm{pH} 8.0$ (in the case of claudin-1; Beijing Zhongshan Golden Bridge Biotechnology Co., Ltd.) for $15 \mathrm{~min}$, and gradually cooled down to room temperature. The sections were then incubated overnight with the appropriate anti-cyclin B1 or anti-claudin-1 antibodies in a humidified chamber at $4^{\circ} \mathrm{C}$. The sections were then washed 3 times with PBS, incubated for $20 \mathrm{~min}$ at room temperature in a humidified chamber with reagent 1 (polymer auxiliary agent; Beijing Zhongshan Golden Bridge Biotechnology Co., Ltd.), washed again with PBS, and incubated for $30 \mathrm{~min}$ at $37^{\circ} \mathrm{C}$ with poly-horseradish peroxidase anti-mouse immunoglobulin G (catalog no. PV-9000; ready to use; Beijing Zhongshan Golden Bridge Biotechnology Co., Ltd.). Next, the sections were washed with a developing solution containing 0.06\% 3,3'-diaminobenzidine (Beijing Zhongshan Golden Bridge Biotechnology Co., Ltd.), counterstained with hematoxylin (Beijing Zhongshan Golden Bridge Biotechnology Co., Ltd.), and mounted. Negative control sections were incubated with PBS instead of anti-cyclin B1 or anti-claudin-1 antibodies.

Evaluation of IHC staining and scoring. Sections were microscopically examined by two pathologists, and scored according to the fraction of stained tumor cells and the staining intensity (Table III), with claudin-1 $1^{+}$cells appearing yellow and cyclin $\mathrm{B}^{+}$cells appearing tan or light yellow. For staining grading, the improved Kojima method was used as previously described (15). Cells in 10 randomly selected fields were examined at x400 magnification. The staining intensity and proportion of positive cells were semi-quantitatively determined, with those samples exhibiting a score $<2$ being considered negative (-); those with a score of 2 being considered weakly positive $\left(^{+}\right)$; those with a score of 3-4 being considered moderately positive $\left({ }^{++}\right)$; and those with a score of 5-6 being considered strongly positive $\left({ }^{++}\right)$. All analyses conducted were double-blind, with $\geq 3$ points for high expression and $\leq 2$ points for lower expression. Microscopy was performed using an Olympus microscope (IX71; Olympus Corporation, Tokyo, Japan).

Statistical analysis. Data were analyzed with SPSS statistical software, version 13.0 (SPSS, Inc., Chicago, IL, USA). Mann-Whitney 2-tailed test was performed to compare the expression levels of claudin-1 and cyclin B1 in tumor tissues vs. adjacent noncancerous mucosae. Correlations between these potential markers and the patients' clinicopathological features were analyzed with Pearson's correlation $\chi^{2}$ test. 
Table I. Claudin-1 protein expression and tumor index correlation analysis.

Claudin-1 expression

\begin{tabular}{|c|c|c|c|c|}
\hline \multirow[b]{2}{*}{ Characteristics } & \\
\hline & No. of cases $(\%)$ & Low $(\%)$ & High $(\%)$ & P-value \\
\hline Age, years & & & & 0.175 \\
\hline$<60$ & $54(55.7)$ & $17(17.5)$ & 37 (38.1) & \\
\hline$\geq 60$ & $43(44.3)$ & $9(9.3)$ & $34(35.1)$ & \\
\hline Gender & & & & 0.055 \\
\hline Female & $9(9.3)$ & $5(5.2)$ & $4(4.1)$ & \\
\hline Male & $88(90.7)$ & $21(21.6)$ & $67(69.1)$ & \\
\hline Tobacco smoking & & & & 0.085 \\
\hline None or limited & $19(19.6)$ & $8(8.2)$ & $11(11.3)$ & \\
\hline Excessively & $78(80.4)$ & $18(18.6)$ & $60(61.9)$ & \\
\hline Alcohol consumption & & & & 0.069 \\
\hline None or limited & $35(36.1)$ & $13(13.4)$ & $22(22.7)$ & \\
\hline Excessively & $62(63.9)$ & $13(13.4)$ & $49(50.5)$ & \\
\hline Degree of differentiation & & & & 0.004 \\
\hline Well & $25(25.8)$ & $13(13.4)$ & $12(12.4)$ & \\
\hline Moderate & $37(38.1)$ & $7(7.2)$ & $30(30.9)$ & \\
\hline Poor & $35(36.1)$ & $6(6.2)$ & $29(29.9)$ & \\
\hline TNM stage & & & & 0.221 \\
\hline $\mathrm{I}+\mathrm{II}$ & $18(18.6)$ & $3(3.1)$ & $15(15.5)$ & \\
\hline $\mathrm{III+IV}$ & $79(81.4)$ & $23(23.7)$ & $56(57.7)$ & \\
\hline Lymph node metastasis & & & & 0.026 \\
\hline No & $35(36.1)$ & $14(14.4)$ & $21(21.6)$ & \\
\hline Yes & $62(63.9)$ & $12(12.4)$ & $50(51.5)$ & \\
\hline
\end{tabular}

TNM, tumor-node-metastasis.

Survival analyses were conducted with the log-rank test method. $\mathrm{P}<0.05$ was considered to indicate a statistically significant difference.

\section{Results}

IHC analysis of claudin-1 and cyclin B1 expression in HSCC tissues and noncancerous mucosae. IHC was performed to evaluate the expression levels of claudin-1 and cyclin B1 in 97 carcinomas (HSCCs) and 90 adjacent noncancerous mucosae. The results indicate that claudin-1 was expressed in the cell membrane and cytoplasm, although mainly in the cytoplasm around the nuclear membrane (Fig. 1A). Claudin-1 expression was heterogenous, with certain regions being diffuse and others presenting a focal area, while cyclin B1 expression was detected in the cytoplasm (Fig. 1B). Low expression of claudin-1 was not detected in the cell membrane or cytoplasm (Fig 1C), and low expression of cyclin B1 was not detected in the cytoplasm (Fig 1D). High expression levels of claudin-1 were observed in 73.2\% (71/97) of tumors and $30 \%(27 / 90)$ of adjacent noncancerous mucosae, while high expression levels of cyclin B1 were observed in $64.9 \%$ (63/97) of tumors and $23.3 \%$ (21/90) of adjacent noncancerous mucosae. These differences were observed to be statistically significant.
Claudin-1 and cyclin B1 protein expression and tumor index correlation analysis. The results of Pearson's correlation $\chi^{2}$ test revealed that claudin-1 expression was associated with tumor differentiation degree $(\mathrm{P}=0.004)$ and lymph node metastasis $(\mathrm{P}=0.026$; Table $\mathrm{I})$, while cyclin $\mathrm{B} 1$ expression was associated with tumor differentiation degree $(\mathrm{P}=0 / 002$; Table II) in patients with HSCC. No correlations were observed between other clinicopathological indices and cyclin B1 or claudin-1 expression.

Claudin-1 and cyclin B1 protein expression and patient survival rate. Log-rank test of 97 HSCC patients who were followed-up for 3-5 years demonstrated that the patient survival rate was significantly lower in patients with high expression levels of claudin-1, compared with patients with low expression levels of claudin-1 $(51.71 \pm 4.02 \%$ vs. $31.78 \pm 2.09 \%$; $\mathrm{P}=0.003$; Fig. 2A). Furthermore, patients with high expression levels of cyclin B1 exhibited a lower survival rate, compared with patients with those exhibiting low expression levels of cyclin $\mathrm{B} 1$ (43.06 $\pm 4.25 \%$ vs. $38.06 \pm 3.11 \%$; $\mathrm{P}=0.305)$, although this was not statistically significant (Fig. 2B).

Correlation of claudin-1 and cyclin B1 protein expression. Among the $71 \mathrm{HSCC}$ cases with high expression levels of claudin-1 identified in the present study, there were 56 cases 
Table II. Cyclin B1 protein expression and tumor index correlation analysis.

Cyclin B1 expression

\begin{tabular}{|c|c|c|c|c|}
\hline \multirow[b]{2}{*}{ Characteristics } & \\
\hline & No. of cases (\%) & Low $(\%)$ & High (\%) & P-value \\
\hline Age, years & & & & 0.135 \\
\hline$<60$ & $54(55.7)$ & $22(22.7)$ & $32(33.0)$ & \\
\hline$\geq 60$ & $43(44.3)$ & $12(12.4)$ & $31(32.0)$ & \\
\hline Gender & & & & 0.162 \\
\hline Female & $9(9.3)$ & $5(5.2)$ & $4(4.1)$ & \\
\hline Male & $88(90.7)$ & $29(29.9)$ & $59(60.8)$ & \\
\hline Tobacco smoking & & & & 0.322 \\
\hline None or limited & 19 (19.6) & $8(8.2)$ & $11(11.3)$ & \\
\hline Excessively & $78(80.4)$ & $26(26.8)$ & $52(53.6)$ & \\
\hline Alcohol consumption & & & & 0.077 \\
\hline None or limited & $35(36.1)$ & $16(16.5)$ & 19 (19.6) & \\
\hline Excessively & $62(63.9)$ & $18(18.6)$ & $44(45.4)$ & \\
\hline Degree of differentiation & & & & $<0.001$ \\
\hline Well & $25(25.8)$ & 18 (18.6) & $7(7.2)$ & \\
\hline Moderate & $37(38.1)$ & $8(8.2)$ & 29 (29.9) & \\
\hline Poor & $35(36.1)$ & $8(8.2)$ & $27(27.8)$ & \\
\hline TNM stage & & & & 0.548 \\
\hline $\mathrm{I}+\mathrm{II}$ & $18(18.6)$ & $6(6.2)$ & $12(12.4)$ & \\
\hline III+IV & $79(81.4)$ & $28(28.9)$ & $51(52.6)$ & \\
\hline Lymph node metastasis & & & & 0.161 \\
\hline No & $35(36.1)$ & $15(15.5)$ & $20(20.6)$ & \\
\hline Yes & $62(63.9)$ & 19 (19.6) & $43(44.3)$ & \\
\hline
\end{tabular}

TNM, tumor-node-metastasis.

Table III. Stained tumor cells and staining intensity for claudin-1.

\begin{tabular}{lc}
\hline Staining & Score \\
\hline Intensity & \\
Negative & 0 \\
Weak intensity & 1 \\
Moderate intensity & 2 \\
Strong intensity & 3 \\
Percentage of positive cells & \\
$<10 \%$ & 0 \\
$10-40 \%$ & 1 \\
$40-70 \%$ & 2 \\
$>70 \%$ & 3 \\
\hline
\end{tabular}

with high expression levels of cyclin Bl. Furthermore, of the 34 cases with low cyclin B1 expression analyzed in the present study, 19 cases also exhibited low claudin-1 expression. The results of Pearson's correlation indicated that cyclin B1 and claudin-1 expression were significantly correlated ( $r=0.482 ; \mathrm{P}=0.0003$; Table IV).
Table IV. Claudin-1 and cyclin B1 correlation analysis in head and neck squamous cell carcinoma tissues.

\begin{tabular}{lcccc}
\hline & \multicolumn{3}{c}{ Cyclin B1 expression, $\mathrm{n}$} \\
\cline { 2 - 4 } Claudin-1 expression & Low & High & Total & P-value \\
\hline Low & 19 & 7 & 26 & \\
High & 15 & 56 & 71 & \\
Total & 34 & 63 & 97 & 0.0003 \\
\hline
\end{tabular}

\section{Discussion}

Cyclin B1 is important in controlling cells in the G2/M phase and in regulating the mitotic entry by forming a complex with CDK1 $(41,42)$. Under physiological conditions, cyclin B1 is activated at the beginning of the $\mathrm{S}$ phase, and is localized in the cell cytoplasm during the G2 phase (43). Cyclin B1 is combined with CDK1 to form the mitosis-promoting factor, which adjusts the G2/M cell cycle checkpoint to promote the transition from $\mathrm{G} 2$ to $\mathrm{M}$ phase and initiate mitosis (44). In the middle and late phases of mitosis, cyclin B1 is degraded by the anaphase promoting complex via the ubiquitin proteasome 
A

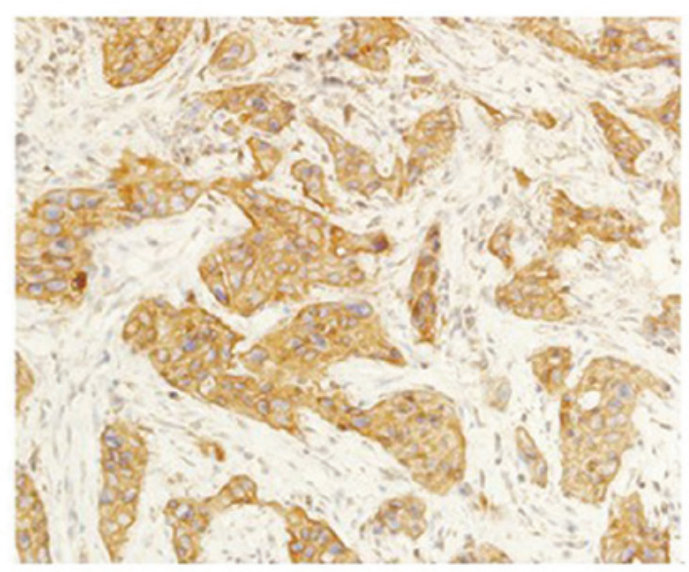

C

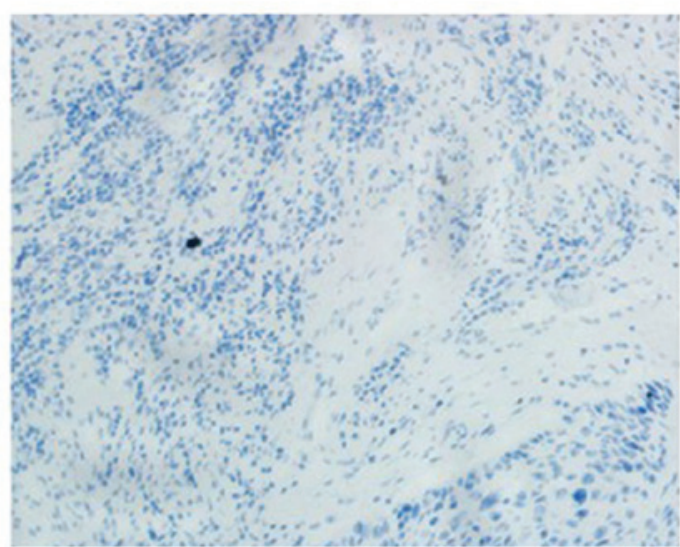

B

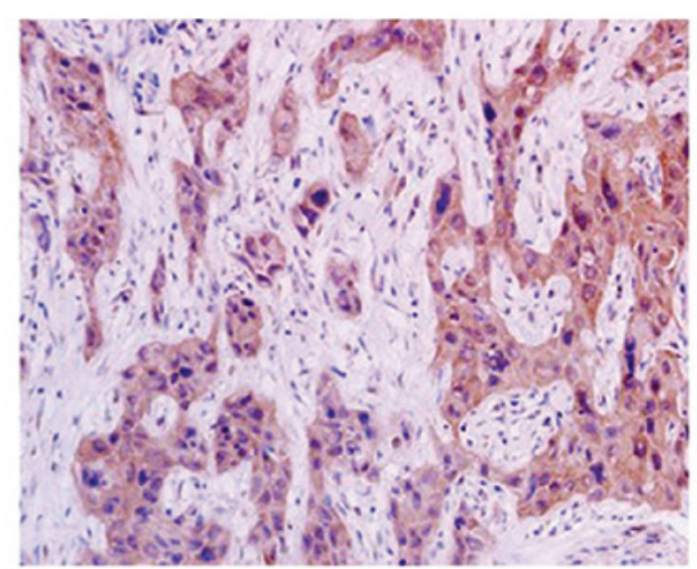

D

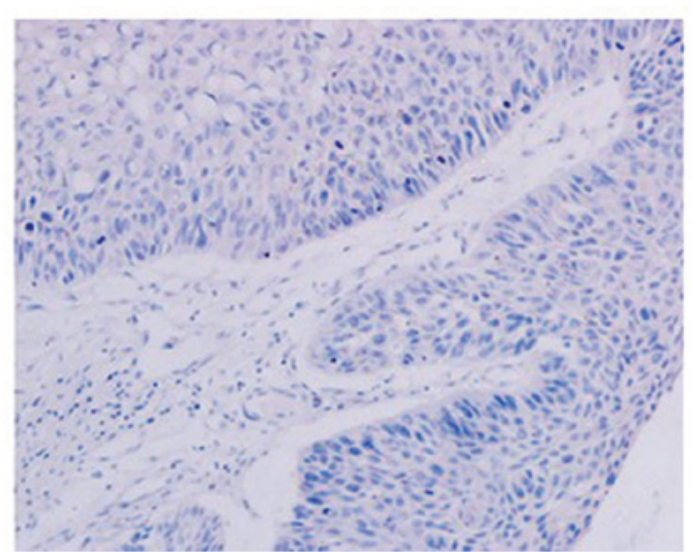

Figure 1. Representative examples of immunohistochemistry. High expression levels of (A) claudin-1 and (B) cyclin B1 in head and neck squamous cell carcinoma tissues. Low expression levels of (C) claudin-1 and (D) cyclin B1 in adjacent noncancerous mucosae (magnification, x200).

A

\section{Survival proportions}

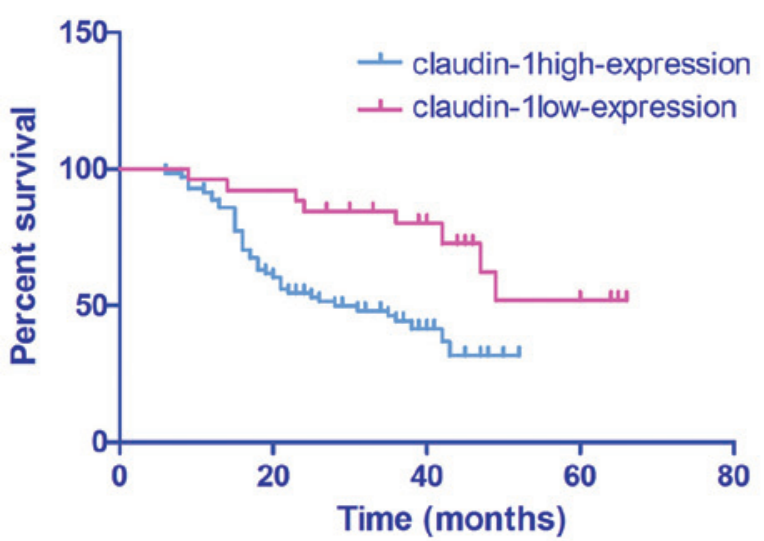

B

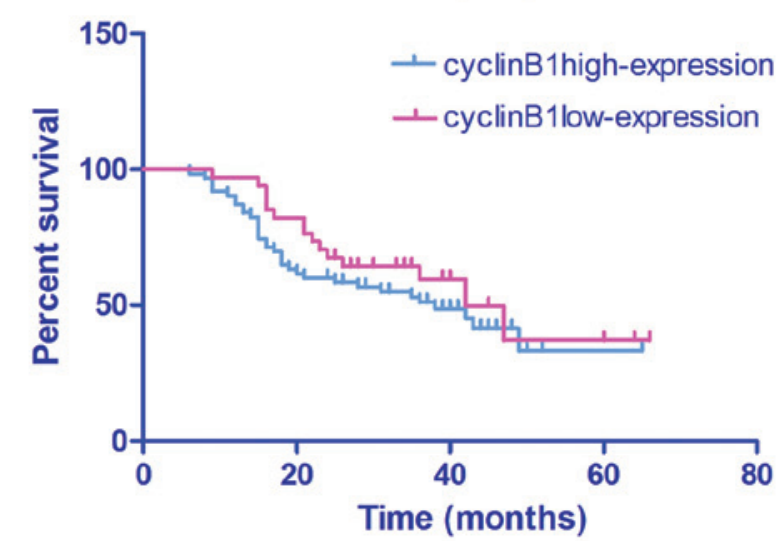

Figure 2. Kaplan-Meier survival plots for high vs. low expression of (A) claudin-1 and (B) cyclin B1 in patients with hypopharyngeal squamous cell carcinoma.

pathway, which results in chromosome depolymerization, nucleoli and nuclear membrane regeneration, and completion of the cell cycle following cytokinesis (45). During the interphase, cyclin B1 is localized in the cytoplasm, mainly around the nuclear membrane, and its orientation is influenced by cell retention signals (46).

A previous study demonstrated that elevated cyclin B1 expression altered the spindle checkpoint via different mechanisms, caused chromosomal instability, led to an abnormal cell division and promoted tumor development in squamous cell carcinoma (47). Previous studies have also noted increased levels of cyclin B1 in malignant tumors, including breast (30), gastric (31), early non-small cell lung (32), colorectal (33), prostate (34), esophageal (37,38), tongue and lung cancer (15), which suggests that cyclin B1 may be a potential tumor marker. The present results revealed that cyclin B1 expression was mainly localized in the cytoplasm of malignant cells, with 63/97 HSCC patients displaying positive 
expression for cyclin B1, compared with the levels observed in normal tissues adjacent to the carcinomas $(\mathrm{P}<0.05)$. Additionally, cyclin B1 expression was observed to be associated with the degree of differentiation of the tumor $(\mathrm{P}<0.05)$, but not with the index of clinical pathology. These findings were consistent with previous studies reporting that cyclin B1 overexpression led to cell cycle disorders or G2/M checkpoint dysregulation, causing uncontrolled proliferation and eventually tumor formation (48). In the present study, Kaplan-Meier analysis revealed that the survival rates of HSCC patients with high expression levels of cyclin B1 were not statistically different from those exhibited by patients with low cyclin B1 expression levels. However, in previous studies on esophageal (37), tongue (39) and non-small cell lung cancer (32), cyclin B1 overexpression was observed to be associated with patient survival. Considering that multiple factors may influence survival, and that differential expression of cyclin B1 has been reported in different tissues, the potential correlation between cyclin B1 expression and survival may be different depending on each tissue. Therefore, cyclin B1 cannot be used independently as an index of prognosis in patients with HSCC.

The mechanisms leading to claudin overexpression in tumor tissues are of particular interest. Abnormalities in claudins expression or localization result in abnormal intercellular signaling and promote tumor formation and metastasis (49). Altered claudin-1 expression leads to the destruction of epithelial permeability and barrier function, loss of cell polarity, decrease in intercellular adhesion force and tumor development $(16,23)$. A previous study has reported that increased claudin-1 expression may inhibit E-cadherin expression, thus promoting an increased in the expression levels of the components of the E-cadherin/T-cell factor (TCF) signaling pathway (50). Changes in claudin-1 localization within the cell membrane, alongside a decrease in E-cadherin expression and an increase in the expression of the components of the E-cadherin/TCF signaling pathway, may promote tumor development (50). Claudin-1 expression is elevated in various types of tumors (16-20). In oral squamous cell carcinoma, previous studies noted that elevated claudin-1 expression was associated with vascular and peripheral nerve invasion by the tumor tissue (51). In the present study, claudin-1 expression was significantly higher in HSCC tissues, compared with the expression levels in adjacent tissues, and claudin-1 protein expression was associated with tumor differentiation degree $(\mathrm{P}=0.004)$ and lymph node metastasis $(\mathrm{P}=0.026)$, but not with clinicopathological index. Kaplan-Meier analysis demonstrated that patients with elevated claudin-1 expression exhibited a significantly lower survival rate than patients with low claudin-1 expression. Previous studies have demonstrated that increased claudin-1 expression promotes cell migration and matrix metalloproteinase-2 (MMP-2) activation (52), which leads to an increased tumor invasiveness and often poor prognosis (53). Therefore, claudin-1 may participate in the development of HSCC and lymph node metastasis. The present findings may contribute to improve diagnostics, prognosis assessment and selection of treatment plan in patients with HSCC. To improve overall survival rates, HSCC patients who exhibit elevated claudin-1 expression may require particularly aggressive interventions and intensive combined therapy.

Yoon et al (54) observed that claudin-1 expression was able to enhance the expression and activity of MMP-2, while cyclin Bl was also able to promote the secretion of MMP-2, which results in MMP-2-mediated interstitial degradation, thus facilitating the transition into a cancerous cell (55). Elevated claudin-1 expression may lead to the activation of TCF-lymphoid enhancer-binding factor/beta-catenin (52), which contains a transcription factor capable of inducing the expression of genes involved in cell proliferation, survival and invasiveness (56), thus regulating the cell cycle in cancer cells. Of the HSCC patients examined in the present study, 71 cases exhibited increased claudin-1 expression, and 63 cases exhibited elevated cyclin B1 expression, which were significantly correlated $(\mathrm{P}<0.001)$. These findings indicate that claudin-1 may be involved in cell cycle regulation and cellular differentiation.

In the present study, IHC analysis confirmed that claudin-1 and cyclin B1 exhibited significantly high expression in HSCC tissues, compared with matched adjacent tissues. Further studies on a larger number of specimens are required in order to validate these preliminary observations. In addition, the messenger RNA expression levels of claudin-1 and cyclin B1 in HSCC and matched adjacent tissues should be analyzed in future studies via reverse transcription-quantitative polymerase chain reaction to further support the present results. Furthermore, the percentage of expression of claudin-1 and cyclin B1 in HSCC specimens should be assessed in future studies in order to evaluate the use potential use of claudin-1 and cyclin B1 as HSCC tumor markers.

In conclusion, the present study demonstrated an elevated cyclin B1 and claudin-1 expression in HSCC specimens, thus suggesting the use of these proteins as tumor markers. Cyclin $\mathrm{B} 1$ expression is associated with the degree of tumor differentiation in patients with $\mathrm{HSCC}$, while claudin-1 expression was associated with the degree of tumor differentiation and lymph node metastasis in these patients. Furthermore, the expression of cyclin B1 and the expression of claudin-1 are significantly correlated in patients with HSCC. Therefore, joint detection of claudin-1 and cyclin B1 may aid to guide cancer therapy and prognosis determination in these patients. Additionally, claudin-1 is associated with survival, and may be used as a monitoring indicator. Overall, the present findings suggest the use of cyclin B1 and claudin-1 as potential novel targets for the treatment of HSCC.

\section{Acknowledgements}

The present study was supported by the Shandong Provincial Natural Science Foundation (Jinan, China; grant no. ZR2013HM107). The authors would like to thank all the patients who participated in the study, in addition to LetPub (www.letpub.com; Woburn, MA, USA) for the linguistic assistance provided during the preparation of the present manuscript.

\section{References}

1. Wittekindt C, Wagner S, Mayer CS and Klußmann JP: Basics of tumor development and importance of human papilloma virus (HPV) for head and neck cancer. Laryngorhinootologie 91 (Suppl 1): S1-S26, 2012 (In German).

2. Landis SH, Murray T, Bolden S and Wingo PA: Cancer statistics, 1999. CA Cancer J Clin 49: 8-31, 1999.

3. Hall SF, Groome PA, Irish J and O'Sullivan B: The natural history of patients with squamous cell carcinoma of the hypopharynx. Laryngoscope 118: 1362-1371, 2008. 
4. Wu S, Gu JC, Liang J, Yu T, Dong XH: Expression and clincal significance of Survivin and PTEN in hypopharyngeal squamous cell carcinoma. Guangdong Yi Xue 33: 1958-1960, 2012 (In Chinese)

5. Lang S, Wollenberg B, Dellian M, et al: Clinical and epidemiological data of patients with malignomas of the head and neck. Laryngorhinootologie 81: 499-508, 2002 (In German).

6. Boyle P and Ferlay J: Cancer incidence and mortality in Europe, 2004. Ann Oncol 16: 481-488, 2005.

7. Rose BS, Jeong JH, Nath SK, Lu SM and Mell LK: Population-based study of competing mortality in head and neck cancer. J Clin Oncol 29: 3503-3509, 2011.

8. Takes RP, Strojan P, Silver CE, Bradley PJ, Haigentz M Jr, Wolf GT, Shaha AR, Hartl DM, Olofsson J, Langendijk JA, et al; International Head and Neck Scientific Group: Current trends in initial hypopharyngeal cancer: The declining use of open surgery. Head Neck 34: 270-281, 2012.

9. Srinivas PR, Kramer BS and Srivastava S: Trends in biomarker research for cancer detection. Lancet Oncol 2: 698-704, 2001.

10. González-Mariscal L, Betanzos A, Nava P and Jaramillo BE: Tight junction proteins. Prog Biophys Mol Biol 81: 1-44, 2003.

11. Gumbiner BM: Cell adhesion: The molecular basis of tissue Architecture and morphogenesis. Cell 84: 345-357, 1996.

12. Heiskala M, Peterson PA and Yang Y: The roles of claudin superfamily proteins in paracellular transport. Traffic 2: 93-98, 2001.

13. Chambers AF, Groom AC and MacDonald IC: Dissemination and growth of cancer cells in metastatic sites. Nat Rev Cancer 2: 563-572, 2002

14. Harhaj NS and Antonetti DA: Regulation of tight junctions and loss of barrier function in pathophysiology. Int $\mathbf{J}$ Biochem Cell Biol 36: 1206-1237, 2004

15. Ishida M, Kushima R and Okabe H: Claudin expression in rectal well-differentiated endocrine neoplasms (carcinoid tumors). Oncol Rep 21: 113-117, 2009.

16. Fritzsche FR, Oelrich B, Johannsen M, Kristiansen I, Moch H Jung $\mathrm{K}$ and Kristiansen G: Claudin-1 protein expression is a prognostic marker of patient survival in renal cell carcinomas. Clin Cancer Res 14: 7035-7042, 2008.

17. Soini Y and Talvensaari-Mattila A: Expression of claudins 1,4,5, and 7 in ovarian tumors of diverse types. Int J Gynecol Pathol 25 . 330-335, 2006

18. Resnick MB, Gavilanez M, Newton E, Konkin T, Bhattacharya B Britt DE, Sabo E and Moss SF: Claudin expression in gastric adenocarcinomas: A tissue microarray study with prognostic correlation. Hum Pathol 36: 886-892, 2005.

19. Huo Q, Kinugasa T, Wang L, Huang J, Zhao J, Shibaguchi H, Kuroki M, Tanaka T, Yamashita Y, Nabeshima K, et al: Claudin-1 protein is a major factor involved in the tumorigenesis of colorectal cancer. Anticancer Res 29: 851-857, 2009.

20. de Oliveira SS, de Oliveira IM, De Souza W and Morgado-DíazJA Claudins upregulation in human colorectal cancer. FEBS Lett 579: 6179-6185, 2005.

21. Krämer F, White K, Kubbies M, Swisshelm K and Weber BH: Genomic organization of claudin- 1 and its assessment in hereditary and sporadic breast cancer. Hum Genet 107: 249-256, 2000.

22. Tokés AM, Kulka J, Paku S, Szik A, Páska C, Novák PK, Szilák L, Kiss A, Bögi K and Schaff Z: Claudin- $1,-3$ and -4 proteins and mRNA expression in benign and malignant breast lesions: A research study. Breast Cancer Res 7: R296-R305, 2005.

23. Chao YC, Pan SH, Yang SC, Yu SL, Che TF, Lin CW, Tsai MS, Chang GC, Wu CH, Wu YY, et al: Claudin-1 is a metastasis suppressor and correlates with clinical outcome in lung adenocarcinoma. Am J Respir Crit Care Med 179: 123-133, 2009.

24. Swisshehn K, Macek R and Kubbies M: Role of claudins in tumorigenesis. Adv Drug Deliv Rev 57: 919-928, 2005.

25. Hsueh C, Chang YS, Tseng NM, Liao CT, Hsueh S, Chang $\mathrm{JH}, \mathrm{Wu}$ IC and Chang KP: Expression pattern and prognostic significance of claudins 1,4 , and 7 in nasopharyngeal carcinoma. Hum Pathol 41: 944-950, 2010.

26. Elledge SJ: Cell cycle checkpoints: Preventing an identity crisis. Science 274: 1664-1672, 1996.

27. Sherr CJ: Cancer cell cycles. Science 274: 1672-1677, 1996.

28. Karagoz ID, Ozaslan M, Cengiz B, Kalender ME, Kilic IH, Oztuzcu S, Gogebakan B and Demiryurek AT: CDC 25A gene $263 \mathrm{C} / \mathrm{T},-350 \mathrm{C} / \mathrm{T}$ and $-51 \mathrm{C} / \mathrm{G}$ polymorphisms in breast carcinoma. Tumour Biol 31: 597-604, 2010.

29. Brandeis M, Rosewell I, Carrington M, Crompton T, Jacobs MA, Kirk J, Gannon J and Hunt T: Cyclin B2-null mice develop normally and are fertile whereas cyclin B1-null mice die in utero. Proc Natl Acad Sci USA 95: 4344-4349, 1998
30. Barrett KL, Demiranda D and Katula KS: Cyclin b1 promoter activity and functional cdk1 complex formation in G1 phase of human breast cancer cells. Cell Biol Int 26: 19-28, 2002

31. Yasuda M, Takesue F, Inutsuka S, Honda M, Nozoe T and Korenaga D: Overexpression of cyclin B1 in gastric cancer and its clinicopathological significance: An immunohistological study. J Cancer Res Clin Oncol 28: 412-416, 2002.

32. Soria JC, Jang SJ, Khuri FR, Hassan K, Liu D, Hong WK and Mao L: Overexpression of cyclin B1 in early-stage non-small cell lung cancer and its clinical implication. Cancer Res 60: 4000-4004, 2000

33. Grabsch H, Lickvers K, Hansen O, Takeno S, Willers R, Stock W, Gabbert HE and Mueller W: Prognostic value of cyclin B1 protein expression in colorectal cancer. Am J Clin Pathol 122: 511-516, 2004.

34. Mashal RD, Lester S, Corless C, Richie JP, Chandra R, Propert KJ and Dutta A: Expression of cell cycle-regulated proteins in prostate cancer. Cancer Res 56: 4159-4163, 1996.

35. Song Y, Zhao C, Dong L, Fu M, Xue L, Huang Z, Tong T, Zhou Z, Chen A, Yang Z, et al: Overexpression of cyclin B1 in human esophageal squamous cell carcinoma cells induces tumor cell invasive growth and metastasis. Carcinogenesis 29: 307-315, 2008.

36. Zhao M, Kim YT, Yoon BS, Kim SW, Kang MH, Kim SH, Kim JH, Kim JW and Park YW: Expression profiling of cyclin B1 and D1 in cervical carcinoma. Exp Oncol 28: 44-48, 2006.

37. Murakami H,Furihata M,Ohtsuki Y and Ogoshi S: Determination of the prognostic significance of cyclin B1 overexpression in patients with esophageal squamous cell carcinoma. Virchows Arch 434: 153-158, 1999.

38. Takeno S, Noguchi T, Kikuchi R, Uchida Y, Yokoyama S and Müller W: Prognostic value of cyclin B1 in patients with esophageal squamous cell carcinoma. Cancer 94: 2874-2881, 2002.

39. Hassan KA, El-Naggar AK, Soria JC, Liu D, Hong WK and Mao L: Clinical significance of cyclin B1 protein expression in squamous cell carcinoma of the tongue. Clin Cancer Res 7: 2458-2462, 2001

40. Sobin LH, Gospodarowicz MK and Wittekind C (eds): TNM Classification of Malignant Tumors, 7th Edition. Wiley-Blackwell, Hoboken, NJ, 2009.

41. Yuan J, Krämer A, Matthess Y, Yan R, Spänkuch B, Gätje R, Knecht R, Kaufmann M and Strebhardt K: Stable gene silencing of cyclin B1 in tumor cells increases susceptibility to taxol and leads to growth arrest in vivo. Oncogene 25: 1753-1762, 2006.

42. Stark GR and Taylor WR: Control of the G2/M transition. Mol Biotechnol 32: 227-248, 2006.

43. Nurse P: Ordering S phase and $M$ phase in the cell cycle. Cell 79: 547-550, 1994.

44. Nigg EA: The substrates of the cdc2 kinase. Semin Cell Biol 2: 261-270, 1991.

45. Farhana L, Dawson M, Rishi AK, Zhang Y, Van Buren E, Trivedi C, Reichert U, Fang G, Kirschner MW and Fontana JA: Cyclin B and E2F-1 expression in prostate carcinoma cells treated with the novel retinoid CD437 are regulated by the ubiquitin- mediated pathway. Cancer Res 62: 3842-3849, 2002.

46. Cukier IH, Li Y and Lee JM: Cyclin B1/Cdkl binds and phosphorylates filamin A and regulates its ability to cross-link actin. FEBS Lett 581: 1661-1672, 2007.

47. Hoffmann TK, Trellakis S, Olulicz K, Schuler P, Greve J, Arnolds J, Bergmann C, Bas M, Lang S, Lehnerdt G,et al. Cyclin B1 Expression and p53 Status in Squamous Cell Carcinomas of the Head and Neck.A NTICANCER R ESEARCH 31: 3151-3158 (2011).

48. Barascu A, Besson P, Le Floch O, Bougnoux P and Jourdan ML: CDK1-cyclin B1 mediates the inhibition of proliferation induced by omega-3 fatty acids in MDA-MB-231 breast cancer cells. Int J Biochem Cell Biol 38: 196-208, 2006.

49. Krause G, Winkler L, Mueller SL, Haseloff RF, Piontek J and Blasig IE: Structure and function of claudins. Biochim Biophys Acta 1778: 631-645, 2008.

50. Dhawan P, Singh AB, Deane NG, No Y, Shiou SR, Schmidt C, Neff J, Washington MK and Beauchamp RD: Claudin-1 regulates cellular transformation and metastatic behavior in colon cancer. J Clin Invest 115: 1765-1776, 2005.

51. Dos Reis PP, Bharadwaj RR, Machado J, Macmillan C, Pintilie M, Sukhai MA, Perez-Ordonez B, Gullane P, Irish J and Kamel-Reid S: Claudin 1 overexpression increases invasion and is associated with aggressive histological features in oral squamous cell carcinoma. Cancer 113: 3169-3180, 2008 
52. Oku N, Sasabe E, Ueta E, Yamamoto T and Osaki T: Tight junction protein claudin-1 enhances the invasive activity of oral squamous cell carcinoma cells by promoting cleavage of laminin-5 gamma2 chain via matrix metalloproteinase (MMP)-2 and membrane-type MMP-1. Cancer Res 66: 5251-5257, 2006.

53. de la Peña S, Sampieri CL and León-Córdoba K: Matrix metalloproteases as molecular markers in gastric cancer. Med Clin (Barc) 134: 123-126, 2010 (In Spanish).

54. Yoon CH, Kim MJ, Park MJ, Park IC, Hwang SG, An S, Choi YH, Yoon G and Lee SJ: Claudin-1 acts through c-Abl-protein kinase Cdelta (PKCdelta) signaling and has a causal role in the acquisition of invasive capacity in human liver cells. J Biol Chem 285: 226-233, 2010
55. Kawamoto H, Uozumi T, Kawamoto K, Arita K, Yano $\mathrm{T}$ and Hirohata T: Type IV collagenase activity and cavernous sinus invasion in human pituitary adenomas. Acta Neurochir (Wien) 138: 390-395, 1996.

56. Arabzadeh A, Troy TC and Turksen K: Role of the Cldn6 cytoplasmic tail domain in membrane targeting and epidermal differentiation in vivo. Mol Cell Biol 26: 5876-5887, 2006. 